\title{
C. Silva-Corvalán y A. Enrique-Arias, Sociolingüística y pragmática del es- pañol, Segunda edición, Washington DC, Georgetown University Press, 2017, 410 pp.
}

La lengua es una de las herramientas con las que cuenta el ser humano para la expresión de sus necesidades sociales. Lengua y sociedad se entrelazan de diversas maneras, estableciéndose relaciones entre ambas significativas. Precisamente la obra Sociolingüística y pragmática del español se centra en el examen de estas relaciones y de las metodologías desarrolladas para estudiarlas. La segunda edición mantiene, en términos generales, la intención y estructura de la anterior ( $\tan$ solo añade el tercer capítulo), sin embargo, incorpora una necesaria revisión y actualización del contenido debido a los continuos avances teórico, metodológicos y bibliográficos de la sociolingüística y de la pragmática del español en los últimos años.

Con este libro, Silva-Corvalán, profesora de la Universidad del Sur de California, y Enrique-Arias, profesor de la Univeritat de les Illes Balears, facilitan la tarea tanto de futuros sociolingüistas como de lingüistas profesionales y avanzados, pues ponen a su disposición no solo los avances que han experimentado ambas disciplinas, sino también reflexiones y análisis relevantes, a través de un lenguaje accesible, claro y con rigor científico.

La obra está dividida en ocho capítulos en los que se discuten conceptos y principios básicos de la sociolingüística y la pragmática de la comunicación oral: los conceptos de lengua, variación y dialecto; las relaciones entre sociolingüística y educación; los métodos sociolingüísticos; las actitudes lingüísticas; la teoría de la variación; variación fonológica, sintáctica y morfosintáctica; el análisis del discurso; el cambio lingüístico; el bilingüismo y el español en los Estados Unidos. Cada capítulo refleja las numerosas publicaciones del mundo hispánico que han servido de base para este libro y concluye con una serie de preguntas de comprensión y unos ejercicios de reflexión, fundamentales para las futuras tareas en la investigación sociolingüística y pragmática. Cierran la obra un apéndice de la guía básica de codificación de la variable expresión de sujeto pronominal, empleada en el Proyecto para el Estudio Sociolingüístico del Español de España y de América (PRESEEA) ${ }^{1}$, y una dilatada y actualizada bibliografía, de más de treinta páginas.

A modo introductorio, el primer capítulo está destinado a presentar y definir el marco teórico de la sociolingüística, precisando los conceptos de lengua, variación y dialecto. Esta disciplina abarca una extensa gama de intereses relacionados con el estudio de una o más lenguas en su entorno social. Delimitar esta disciplina es tarea

\footnotetext{
${ }^{1}$ Proyecto cuyo objetivo es la creación de un corpus de lengua española hablada representativo del mundo hispánico en su variedad geográfica y social, a través de materiales que se reúnen atendiendo a la diversidad sociolingüística de las comunidades de habla hispanohablantes.
} 
difícil pues los fenómenos tanto lingüísticos como sociales relativos a la sociolingüística son de naturaleza compleja. Silva-Corvalán y Enrique-Arias definen la sociolingüística (p. 1), en sentido amplio, como el estudio de aquellos fenómenos lingüísticos que tienen relación con factores de tipo social. A lo largo de este primer capítulo, los autores indican cuáles son estos factores sociales: diferentes sistemas de organización política, económica, social y geográfica de una sociedad; factores individuales que tienen repercusiones sobre la organización social, como la edad, la raza, el sexo y el nivel de instrucción; aspectos históricos y étnico-culturales, y el contexto externo (situación inmediata que rodea la interacción). Posteriormente, los autores precisan esta amplia definición, que también sería aplicable a otras disciplinas afines como la sociología del lenguaje, la etnografía, la etnolingüística, la dialectología y la pragmática, llevando a cabo una revisión crítica sobre ellas. Los autores presentan un repaso sobre las aportaciones de estas disciplinas al mundo hispánico que, a su vez, han servido de soporte y base para la propia sociolingüística.

El segundo capítulo está dedicado a cuestiones metodológicas, relativas al diseño de corpus y al proceso de análisis del habla cotidiana. Se examinan algunos métodos y técnicas empleados en estudios sociolingüísticos, teniendo en consideración tanto los avances como los problemas que estos pueden generar. El método sociolingüístico es descriptivo e interpretativo y su objetivo central es dar cuenta de las estructuras de la lengua en el discurso oral primeramente y, secundariamente, en el escrito (si se estudian épocas anteriores a la invención de la grabadora). Como señalan los autores (p. 38), la sociolingüística se caracteriza por su enfoque pancrónico: la variación sincrónica se explica frecuentemente como consecuencia de los procesos de evolución histórica. Tras caracterizar el paradigma metodológico de los estudios sociolingüísticos, los autores detallan los cinco pasos que se deben tener presentes en una investigación de este tipo:

1. Observación de la comunidad e hipótesis de trabajo

2. Selección de los hablantes

3. Recogida de datos

4. Análisis de los datos: cualitativo y cuantitativo

5. Interpretación de los resultados de los análisis

Además, al final del capítulo, se hace mención al desarrollo de la sociolingüística gracias a los aportes de la lingüística de corpus y de la estadística, disciplinas que han facilitado enormemente la posibilidad de acceder y estudiar materiales.

Los siguientes cinco capítulos (del tres al siete) integran un mismo bloque, en el cual se exponen las aplicaciones directas de la sociolingüística. El tercer capítulo está dedicado al estudio de las actitudes lingüísticas, pues esta perspectiva es de gran importancia al dar información acerca de los propios hablantes, su posición dentro de un grupo social, sus valores y sus prejuicios lingüísticos. Así, este tipos de estudios, ya sea abordado desde un método directo o indirecto, resulta crucial para la definición de una comunidad de habla. 
El cuarto capítulo explica la variación sociofonológica. Los autores demuestran que la variación lingüística está condicionada tanto por factores sociales más o menos obvios -como la edad, la clase social y el sexo- como por factores sociales más sutiles, que también deben ser analizados, vinculados a la historia social del individuo y con los grupos sociales con los que se identifica o aspira identificarse. Aunque son numerosos los estudios de variables fonológicas del español (aspiración y elisión de -s final de sílaba, el yeísmo, el debilitamiento y elisión de / d/ intervocálica, entre otros), todavía quedan muchos fenómenos fonológicos que no se han estudiado desde una perspectiva variacionista, como la aspiración de / s / inicial de sílaba o el debilitamiento de la fricativa velar $/ \mathrm{x} /$.

El siguiente apartado continúa con el paradigma variacionista, pero en este caso se detallan la variación sintáctica y morfosintáctica. Ciertamente, la extensión del modelo sociolingüístico al nivel morfológico y al sintáctico generó gran controversia. Mediante diferentes ejemplos, los autores precisan que la problemática que se ha suscitado responde a la cuestión del significado lingüístico, pues ha dificultado la elaboración de un marco teórico que sirva para los estudios cuantitativos de variación morfológica, sintáctica y también léxica.

No es de extrañar que el capítulo seis se ocupe de la pragmática, ya que sus intereses se sitúan próximos a los de la sociolingüística. De hecho, en numerosas ocasiones resulta complicado separar ambas áreas de estudio, como refleja la existencia de los siguientes términos: pragmática social, pragmática sociocultural, pragmática discursiva y sociopragmática. En el nivel lingüístico del análisis del discurso, los autores indican que las nociones de género y registro resultan especialmente relevantes para comprender los procesos de interacción comunicativa. A lo largo de este capítulo, Silva-Corvalán y Enrique-Arias dan una visión, no total pero sí extensa, de la riqueza de las investigaciones sociopragmáticas llevadas a cabo sobre el español, destacando los estudios sobre cortesía, formas de tratamiento y marcadores discursivos.

Uno de los objetivos centrales de la sociolingüística variacionista ha sido la identificación y explicación de los procesos de cambio lingüístico. Por eso en el capítulo siete se tratan la variación y el cambio. El estudio del cambio lingüístico fue iniciado por los neogramáticos, quienes afirmaban que estaba controlado por dos principios fundamentales: la regularidad del cambio fonético y la analogía. A partir de estas primeras aproximaciones al cambio lingüístico, se sucedieron diversas opiniones, como las de los estructuralistas y generativistas. Los autores indican que, gracias a las herramientas metodológicas de la sociolingüística, el análisis de la variación ha podido ser empleado en la lingüística histórica. Además, se delimitan, a través de interesantes gráficos y resultados, cinco principios que subyacen a los fundamentos empíricos de la teoría de la evolución lingüística: restricción, transición, inserción, evaluación y actualización.

El capítulo final de la obra, "Lenguas en contacto y bilingüismo", constata el desarrollo que han experimentado en los últimos años las investigaciones sobre lenguas en contacto. Tras revisar y explicar algunos conceptos fundamentales, como 
lengua pidgin, lengua criolla, bilingüismo social o interferencia, los autores concluyen que su conocimiento resulta de gran utilidad para implantarlo en la enseñanza de segundas lenguas. La explicación de estos conceptos y de las relaciones que se pueden realizar con el contexto social de los hablantes resulta muy útil para utilizar en el marco de la enseñanza, dado que los autores remiten a un marco teórico esencial en la disciplina. El capítulo cierra con un subapartado en el que se detallan los aspectos sociales, demográficos y lingüísticos del español de los Estados Unidos. Los autores concluyen que el grado de contacto con las variedades no restringidas del español, a través de la radio, prensa, televisión, enseñanza, etc., será crucial para la continuidad más o menos estabilizada del español en los Estados Unidos.

En definitiva, podemos situar este complejo trabajo de Silva-Corvalán y EnriqueArias entre las obras de referencia de la investigación sociolingüística del español. No solo porque hace un amplio repaso de los conceptos fundamentales y de los avances en sociolingüística, sino porque abre las puertas a futuras investigaciones y a futuros investigadores en este ámbito gracias, especialmente, a las preguntas de comprensión y ejercicios de reflexión.

Paula Albitre Lamata 